\section{U.S. Southeastern Peach Growers Preferences for Fruit Size and External Color versus Resistance to Brown Rot Disease}

\author{
Zongyu Li ${ }^{1}$, R. Karina Gallardo², Vicki A. McCracken ${ }^{3}$, \\ Chengyan Yue ${ }^{4}$, Ksenija Gasic ${ }^{5}$, Gregory Reighard ${ }^{5}$, \\ and James R. McFerson ${ }^{6}$
}

ADDITIONAL INDEX WORDs. decision making, discrete choice experiment, improved cultivars, Monilinia fructicola, Prunus persica, survey

Summary. U.S. peach (Prunus persica) growers are challenged by the need to protect their orchards from economically damaging diseases and deliver fruit with the quality expectations of the supply chain. This study focuses on the U.S. southeastern peach sector, including North Carolina, South Carolina, Alabama, Virginia, and Georgia. This region offers a useful case to analyze growers' preferences for both fruit quality and disease resistance. We collected primary data from peach operations in 2016 and 2018. In both surveys, a discrete choice experiment was used to advance the understanding of how peach growers in the southeastern United States value fruit quality (i.e., fruit size and external color) vs. disease resistance [i.e., brown rot (Monilinia fructicola)]. The sample of growers surveyed in 2016 growers placed a greater importance on the fruit quality attribute that would imply higher returns, that is, fruit size (expressed as fruit diameter) compared with improvements in brown rot resistance and external fruit color. Meanwhile, the sample of growers surveyed in 2018 placed a higher importance to brown rot resistance and external fruit color compared with fruit size. Findings consistent for the $\mathbf{2}$ years are that growers are willing to pay for larger rather than smaller improvements in brown rot resistance, and that a large improvement in brown rot resistance is more important than external fruit color.

$\mathrm{B}$ ased on perceived human health and environmental concerns, many consumers are increasingly

$\overline{\text { Received for publication } 5 \text { June 2020. Accepted for }}$ publication 28 July 2020.

Published online 27 August 2020.

${ }^{1}$ Medicaid Data Analytics, Louisiana Department of Health, P.O. Box 629, Baton Rouge, LA 70802

${ }^{2}$ School of Economic Sciences, IMPACT Center, Washington State University Puyallup Research and Extension Center, 2606 W. Pioneer Avenue, Puyallup, WA 98371

${ }^{3}$ Extension Administration, Washington State University, P.O. Box 646248, Hulbert Hall, Pullman, WA 99164

${ }^{4}$ Department of Horticultural Science and Department of Applied Economics, University of Minnesota, Twin Cities, 1970 Folwell Avenue, St. Paul, MN 55108

${ }^{5}$ Plant and Environmental Sciences Department, Clemson University, Clemson, SC 29634

${ }^{6}$ Tree Fruit Research and Extension Center, Washington State University, 1100 N. Western Avenue, Wenatchee, WA 98801

Funding for this project was provided by the U.S Department of Agriculture National Institute of Food and Agriculture Specialty Crop Research Initiative project "RosBREED: Combining Disease Resistance with Horticultural Quality" (2014-51181-22378).

R.K.G. is the corresponding author. E-mail: karina gallardo@wsu.edu.

This is an open access article distributed under the $\mathrm{CC}$ BY-NC-ND license (https://creativecommons.org/ licenses/by-nc-nd/4.0/).

https://doi.org/10.21273/HORTTECH04667-20 demanding food products grown with reduced pesticide inputs (Pimentel, 2005). At the same time, consumer expectations for fresh fruits with superior quality in terms of external appearance, flavor, and textural attributes have also increased (Choi et al., 2017; Wang et al., 2017; Zheng et al., 2016). In response, rosaceous crop growers are seeking to invest in cultivars that combine market-demanded fruit quality with durable resistance to major diseases (Iezzoni, 2018); however, improving these sets of attributes, in a single cultivar is difficult to achieve and highly resource-intensive for rosaceous crops such as peach [Prunus persica (Iezzoni, 2018)].

Fresh market fruit growers must mitigate yield and quality losses to pests and diseases but also carefully control variable input costs for their management practices. Using diseaseresistant cultivars is one obvious and attractive strategy to manage their risk. Fresh produce growers usually receive the residual of the market price, which is the price negotiated by the market intermediary minus the cost of receiving, packing, storing, promotion, and other handling operations performed by the intermediary. In some cases, growers do not cover all variable and fixed costs (Cook et al., 2015). Because growers bear a considerable marketing risk-losses during handling or when end-consumers at the retail level do not buy the product-they strive to provide products with quality attributes that consumers most prefer.

This study focuses on the U.S. southeastern peach sector, including North Carolina, South Carolina, Alabama, and Georgia. As of 2018, annual farm gate value for this sector is $\approx \$ 95.4$ million [U.S. Department of Agriculture (USDA), 2019]. This region offers a useful case to analyze growers' preferences for both fruit quality and disease resistance. Southeastern U.S. peach growers have a logistical advantage in supplying highly populated eastern U.S. markets and can also harvest closer to optimal ripeness when the fruit has had time to fully ripen and attain superior flavor profiles (Zhao et al., 2017); however, their seasonally hot, humid, and rainy growing conditions lead to pest and disease incidences that routinely threaten peach operations' profitability (Zhao et al., 2017).

Disease-resistant cultivars could offer southeastern U.S. peach growers a feasible alternative to manage, prevent, and control diseases, obtain economic yields, and maintain their market advantage. However, plant breeding programs face challenges combining disease resistance and fruit quality in one single cultivar (Gallardo et al., 2012; Yue et al., 2012). Host plant resistance to diseases are often found in wild species, along with undesirable fruit attributes like a low level of sugar, high levels of malic acid, undesirable flavors, and small size (Moing et al., 2003).

\begin{tabular}{llll}
\hline $\begin{array}{l}\text { Units } \\
\begin{array}{l}\text { To convert U.S. to SI, } \\
\text { multiply by }\end{array}\end{array}$ & U.S. unit & SI unit & $\begin{array}{l}\text { To convert SI to U.S., } \\
\text { multiply by }\end{array}$ \\
\hline 0.4047 & acre $(\mathrm{s})$ & ha & 2.4711 \\
2.54 & inch(es) & cm & 0.3937
\end{tabular}


Considering the complexity of breeding an improved peach cultivar that appeals to both growers and consumers, groups that sometimes have very different trait priorities, breeding programs must carefully assess the allocation of time and monetary resources. In this context, it would help breeders gain a better understanding of growers' preferences when deciding to adopt a new cultivar. In this study, we investigated the dollar value growers are willing to pay for improved fruit quality and disease resistance attributes in new cultivars. We focused on resistance to brown rot disease, caused by the fungus Monilinia fructicola, which causes significant losses to the southeastern U.S. peach crop (Schnabel et al., 2010) and the fruit quality attributes of size and fruit color (blush). Although the development of resistance to brown rot disease in peach has been limited, it remains an important goal in most breeding programs.

Peaches can be classified according to the harvest time window in early (harvest 15 May-8 June), mid (harvest 9 June-4 July), and late (later than 4 July). Production practices and labor costs differ across these harvest windows. Chavez et al. (2015) and Ritchie et al. (2005) suggested that growers have contrasting perceptions of the importance of fruit quality and disease resistance based on harvest timing. This study addresses that issue directly and specifically examines southeastern peach growers' decision-making process when selecting a new cultivar, considering the late harvest window of 2016 and 2018 . We focus on the late harvest window, as this group exhibits the greatest needs for inputs for brown rot control, as the fruit is on the tree longer. Note that 2016 and 2018 marked 1 year before and after a major freeze event in 2017 in the southeastern peach production regions in which temperature descended below record low temperatures, leading to the worst damage to peach production in 10 years in South Carolina and Georgia (Georgia Department of Agriculture, 2017; South Carolina Department of Agriculture, 2017).

\section{Literature review}

A number of studies that focused on growers' preferences for peach horticultural and fruit quality attributes concluded that taste, external fruit color, size, freedom from defects, firmness, flavor, and sweetness were important for growers' acceptance of a new cultivar (Park and Florkowski, 2003; Yue et al., 2014, 2017; Zhao et al., 2017). Peach operation characteristics, such as sales revenue, impact the perceived importance of peach quality attributes, as operations with higher revenue sales were willing to pay more for improved firmness but less for flavor enhancement (Yue et al., 2017). Similarly, grower sociodemographics also influence the perceived importance of fruit quality, as principal operators who have degrees in higher education (or more advanced degrees) tend to be more accepting of paying more in licensing fees or improved cultivars (Yue et al., 2017).

From the consumer perspective of fruit quality attributes, a number of studies have concluded that flavor, texture, firmness, larger size, and color are important determinants of consumer preferences (Campbell et al., 2013; Delgado et al., 2013; Olmstead et al., 2015). Zhou et al. (2018) identified three market segments of U.S. peach consumers based on their preferences for key attributes: external fruit color, external appearance, size, firmness, sweetness, flavor, and price. The experienced attributeoriented market segment ( $49 \%$ of the sample of respondents) valued fruit taste and texture, the search attributeoriented market segment (34\% of the sample) valued fruit appearance, and the balanced market segment $(18 \%$ of the sample) valued both fruit quality and appearance. Gallardo et al. (2015) elicited peach market intermediaries' preferences for fruit quality attributes and found intermediaries (not in California) were willing to pay a price premium for improved fruit size, sweetness, and firmness.

Building on previous studies, we estimated growers' willingness to pay for fruit quality and disease resistance when considering investing in a new cultivar. Both sets of attributes are important in the dynamic consumers' preferences and tastes. This article addresses a specific region and crop in 2016 and 2018. In addition, having a study specific to a growing region is suitable, as disease pressure differs according to the environmental conditions of a specific production area, and across years, as does the particular production and marketing context of the crop within a region. Nonetheless, the approach and methodology used in this study could apply to other regions and crops.

\section{Methodology}

Data collection. The data were collected via two survey instruments, implemented in 2016 and 2018 , to investigate if there were differences in growers' viewpoints in two different years, considering a consistent harvest window. The survey questions and implementation were kept as identical as possible. In 2016, a list of 308 randomly selected names and mailing addresses of peach growers from North Carolina, South Carolina, and Georgia was procured from Meister Media Worldwide (Willoughby, $\mathrm{OH})$, a company that administers grower magazines in the United States and worldwide. The protocol for distribution was the total design method (Dillman et al., 2009). On 26 Feb. 2016, the survey package, including a paper questionnaire, a cover letter explaining the survey, and a postage-paid return envelope, was sent to each grower. Reminder postcards were sent 1 week later on 7 Mar. 2016 to all growers on the list. The second wave of surveys with replacement questionnaires was sent to growers who had not responded before 7 Apr. 2016. Because of the low response rate by July 2016, a final replacement survey was mailed on 12 July. Of 308 questionnaires initially sent, 49 were returned as ineligible and 33 were returned as completed, representing a response rate of $\approx 13 \%$.

In 2018 , the survey was disseminated by the Peach Team of the Clemson Cooperative Extension at the College of Agriculture, Forestry, and Life Sciences, Clemson University, an interdisciplinary team of researchers and extension agents whose goal is to provide research-based information to advance the peach industry in South Carolina and neighboring states. Data were collected in conjunction with site visits to growers and field days hosted by the team during Jan. to Mar. 2018. A total of 50 responses were obtained. We acknowledge the caveat in the sample selection bias for the 2018 data collection effort. 
Table 1. Example of the choice experiment presented to survey respondents.

\begin{tabular}{|c|c|c|c|}
\hline Peach feature & Option A & Option B & Option C \\
\hline External fruit color & $\begin{array}{l}\text { Yellow background with } 75 \% \text { red } \\
\text { blush color }\end{array}$ & $\begin{array}{l}\text { Yellow background with } 50 \% \text { red } \\
\text { blush color }\end{array}$ & nor B \\
\hline $\begin{array}{l}\text { Brown rot resistance score } \\
\text { where: } \\
0=100 \% \text { susceptible } \\
10=100 \% \text { resistant }\end{array}$ & Score: $3-7$ & Score: $>7$ & \\
\hline $\begin{array}{l}\text { Which option would you } \\
\text { choose? }\end{array}$ & & & \\
\hline
\end{tabular}

Table 2. Attribute levels in discrete choice scenarios in the 2016 and 2018 southeastern U.S. peach growers survey.

\begin{tabular}{lccc}
\hline Cultivar attribute & Level 1 & Level 2 & Level 3 \\
\hline $\begin{array}{l}\text { Peach diameter (inches) } \\
\text { External fruit color }\end{array}$ & 2.5 & 2.75 & 3 \\
& $\begin{array}{c}\text { Yellow background with } \\
\text { red blush color }\end{array}$ & $\begin{array}{c}\text { Yellow background with } 75 \% \\
\text { red blush color }\end{array}$ & 100\% red blush color \\
$\begin{array}{l}\text { Brown rot resistance score where: } \\
0=100 \% \text { susceptible }\end{array}$ & $\begin{array}{l}\text { 0-2: very susceptible } \\
10=100 \% \text { resistant }\end{array}$ & $3-7:$ susceptible & $>7:$ least susceptible \\
Licensing cost - one-time fee $(\$ /$ tree $)$ & $\$ 1$ & $\$ 2$ & $\$ 3$ \\
\hline
\end{tabular}

${ }^{\mathrm{z}} 1$ inch $=2.54 \mathrm{~cm}$.

The pool of respondents was not the same for the two surveys. The 2018 surveys included more of largesized farms and fewer small-sized farms compared with the 2016 survey. Although the intent of the two surveys was the same, changes were made to the 2018 survey because of its implementation and focus on the late harvest season only (i.e., questions not pertaining to the late harvest season were not included). Also, questions in 2018 referred to the last 5 years of production 2012-17, whereas in the 2016 survey questions referred to the previous production year 2015. A question concerning perceived resistance to brown rot for a list of different commonly grown peach cultivars was included in 2016 but not in 2018. Other questions included in both years referred to growers' experiences with brown rot resistance in terms of the percentage of crop damaged and cost of control, questions about the peach operation, and principal operator sociodemographic information. Both surveys were developed in consultation with peach breeders, extension educators, and growers.
To analyze the growers' preferences for different combinations of quality and disease resistance attributes we used a discrete choice approach in both 2016 and 2018 surveys. All attributes combined resulted in a total of $2 \times 3^{3}=54$ combinations, which we considered too many for an individual to reasonably evaluate. To limit the number of choice scenarios, we used a fractional factorial design. The number of choice scenarios in the 2016 and 2018 surveys were different. In 2016 , choice scenarios referred to all three harvest time windows, early, mid, and late. In 2018, choice scenarios referring only to the late harvest season were included. In the 2016 survey, there were three times the number of choice experiment scenarios compared with the 2018 survey. Hence the need to decrease the number of scenarios presented to respondents in 2016. We used block design to create two versions of the questionnaire that differed only in the attribute combination in each choice scenario. The sample of respondents was divided into two groups, and each group randomly received one of the two versions of the questionnaire, that consisted of six scenarios for each time harvest window. The Defficiency of the fractional factorial design was 85.3. For the 2018 survey, because only the late harvest window was included, each individual was presented with six scenarios, and there was only one questionnaire version.

Each choice experiment consistent of a hypothetical situation in which growers had to choose between two peach cultivars to grow. The two alternatives presented differed in the levels of fruit diameter, external fruit color (blush), brown rot resistance, and licensing cost (labeled as Option A and Option B). Growers were asked to choose their preferred alternative and if neither Option A nor Option B was of interest, they could select Option $C$, which was a "neither" option. An example of the choice experiment is presented in Table 1 .

In both surveys, the attributes included in the choice scenarios were fruit color, brown rot resistance, fruit size, and licensing cost. In both surveys there were three levels of fruit 
Table 3. Summary statistics for the southeastern U.S. peach operations and principal operator sociodemographics, responses from surveys conducted in 2016 and 2018.

\begin{tabular}{|c|c|c|}
\hline Item & \multicolumn{2}{|c|}{ Value } \\
\hline \multicolumn{3}{|c|}{ Respondents indicating the state where farm is located (no.) } \\
\hline & 2016 & 2018 \\
\hline Alabama & - & 22 \\
\hline South Carolina & 9 & 11 \\
\hline Georgia & 10 & 7 \\
\hline North Carolina & 13 & 5 \\
\hline Virginia & - & 2 \\
\hline Total & 32 & 47 \\
\hline \multicolumn{3}{|c|}{ Total acres of peaches owned or managed (\% of respondents) } \\
\hline & 2016 & 2018 \\
\hline$<5^{\mathrm{z}}$ & 25 & 10.64 \\
\hline $5-14$ & 25 & 23.4 \\
\hline $15-24$ & 9.38 & 14.89 \\
\hline $25-49$ & 15.63 & 17.02 \\
\hline 50-99 & 6.25 & 6.38 \\
\hline $100-249$ & 9.38 & 4.26 \\
\hline $250-499$ & 0 & 2.13 \\
\hline $500-1,000$ & 3.13 & 6.38 \\
\hline$>1,000$ & 6.25 & 14.89 \\
\hline \multicolumn{3}{|c|}{ Weighted average size per state (acres) } \\
\hline & 2016 & 2018 \\
\hline Georgia & 275.15 & 833.81 \\
\hline South Carolina & 207.11 & 627.16 \\
\hline Virginia & - & 379.75 \\
\hline North Carolina & 11.26 & 15.6 \\
\hline Alabama & - & 30.2 \\
\hline Weighted average ${ }^{y}$ & 148.86 & 303.05 \\
\hline \multicolumn{3}{|c|}{$\begin{array}{l}\text { Self-perceived risk attitude for the principal operator of the peach farm } \\
\text { (rating from } 1 \text { to } 10 ; 1=\text { extremely unwilling to take risk, } 10=\text { extremely willing to take risk) }\end{array}$} \\
\hline & 2016 & 2018 \\
\hline Mean & 6.72 & 5.76 \\
\hline SD & 2.2 & 2.76 \\
\hline
\end{tabular}

${ }^{\mathrm{z}} \mathrm{l}$ acre $=0.4047$ ha.

${ }^{y_{T}}$ The weighted mean was calculated using the median point of the categories.

color: yellow background with $50 \%$ red blush color, yellow background with $75 \%$ red blush color, and $100 \%$ red blush color. Also, in both surveys two levels of fruit size, expressed as fruit diameter, that corresponded to the late harvest window: 2.75 and 3 inches were included. In both surveys, there were three levels of brown rot resistance scores; however, the wording used to describe each level was different. In the 2016 survey, resistance scores 0 to 2,3 to 7 , and $>7$ were used. This reflected a 0 to 10 scale, where 0 was $100 \%$ susceptible and 10 was $100 \%$ resistant to brown rot. Therefore, the 0 to 2 score represented the very susceptible, the 3 to 7 represented the susceptible, and the $>7$ the least susceptible. In the 2018 survey, no scores were used but the wording included least susceptible, susceptible, and very susceptible. In both surveys, there were three levels of licensing cost: $\$ 1, \$ 2$, and $\$ 3$ per tree. Table 2 lists the attributes and the attribute levels used in the choice experiment in both 2016 and 2018 surveys.

EMPIRICAL ESTIMATION. Our empirical estimation builds on the random utility theory. We assume a grower derives utility when he or she sees his or her profits augmented. Growers' profits are a function of expected revenues derived from cultivars with improved fruit quality characteristics and licensing fees resulting from planting a cultivar different from the status quo. The willingness to pay (WTP) estimates in our study measure growers' willingness to invest in growing the improved cultivars. A grower would invest in a cultivar with enhanced attributes only when the perceived benefit from the improved attribute was higher than the corresponding licensing cost. For example, a grower was willing to invest in disease resistance improvement if the perceived marginal increase in revenues brought by the improvement in disease resistance was high enough to cover the marginal decrease in net income brought by the increase in the production cost due to the licensing fees. The theoretical framework of estimating grower WTP values was provided by Lusk and Hudson (2004) and Zapata and Carpio (2014). The same derivation was also used by Gallardo et al. (2015).

We used the mixed logit model for estimation, due to its advantages over other approaches, including its relaxation of the independence of irrelevant alternatives (IIA) assumption, and its ability to model preference heterogeneity across respondents. Suppose the profit for a grower $i(i=1,2, . ., \mathrm{N})$ choosing alternative $j(j=1,2, . ., \mathrm{M})$ is given by the following:

$$
\Pi_{i j}=\alpha+\beta x_{j}+\gamma z_{i}+\varepsilon_{i j}
$$

where $\Pi_{i j}$ is the profit accrued by grower $i$, from choosing alternative $j, \alpha$ is the alternative specific constant (ASC), $x_{j}$ depicts the peach attributes including diameter, external fruit color, brown rot resistance, and licensing cost, presented in each alternative $j ; z_{i}$ are sociodemographic variables related to individual $i$. $\beta$ is the marginal utility of each quality attribute, a vector of random parameters with an estimated mean $u$ and SD $\sigma . \gamma$ represents the effects of the individuals' sociodemographic variable on the marginal utility.

The ASC captures the effect of choosing to grow a peach cultivar as presented in either Option A or Option $\mathrm{B}$; in contrast to the "Neither A or B" option. Because A or B label for each peach cultivar is random and not attached to a known cultivar in our discrete choice experiment, we did not use ASC for each peach cultivar. We used a dummy variable to distinguish the "grow" option (Option A or Option B) from the "do not grow" (Option C) to capture the preferences' heterogeneity for the choice to grow or not to grow a cultivar with 
the characteristics as presented in our scenarios. The "Neither A nor B" option resembles an actual grower decision, which ensures that the respondents were never forced to grow either peach cultivar presented in the

Table 4. Southeastern U.S. peach growers' experiences with brown rot and viewpoints on planting a new cultivar, responses from surveys conducted in 2016 and 2018.

\begin{tabular}{|c|c|c|}
\hline Item & & \\
\hline \multicolumn{3}{|c|}{ Proportion of respondents indicating that they experienced crop loss due to brown rot (\%) } \\
\hline & 2016 & 2018 \\
\hline Percentage & 23.33 & 47.83 \\
\hline \multicolumn{3}{|c|}{$\begin{array}{c}\text { Proportion of respondents who indicated their cost of managing brown rot disease, } \\
\text { corresponded to following categories }\end{array}$} \\
\hline & 2016 & 2018 \\
\hline$\$ 0-\$ 50$ per acre ${ }^{z}$ & 27.59 & 12.77 \\
\hline$\$ 51-\$ 100$ per acre & 31.03 & 38.3 \\
\hline$\$ 101-\$ 200$ per acre & 10.34 & 10.64 \\
\hline$\$ 201-\$ 300$ per acre & 17.24 & 19.15 \\
\hline$\$ 301-\$ 400$ per acre & 10.34 & 4.26 \\
\hline$\$ 401-\$ 500$ per acre & 3.45 & 6.38 \\
\hline More than $\$ 500$ per acre & 0 & 8.51 \\
\hline Weighted avg $(\$ / \text { acre })^{y}$ & 140.5 & 224.47 \\
\hline \multicolumn{3}{|c|}{$\begin{array}{c}\text { Proportion of respondents who indicated their variable production costs (operating, } \\
\text { harvesting, and packing), corresponded to the following categories }\end{array}$} \\
\hline & 2016 & 2018 \\
\hline$\$ 0-\$ 2,000$ per acre & 51.72 & 43.48 \\
\hline$\$ 2,001-\$ 3,000$ per acre & 24.14 & 19.57 \\
\hline$\$ 3,001-\$ 4,000$ per acre & 13.79 & 13.04 \\
\hline$\$ 4,001-\$ 5,000$ per acre & 0 & 10.87 \\
\hline$\$ 5,001-\$ 6,000$ per acre & 3.45 & 10.87 \\
\hline$\$ 6,001-\$ 7,000$ per acre & 3.45 & 2.17 \\
\hline$\$ 7,001-\$ 8,000$ per acre & 3.45 & 0 \\
\hline$\$ 8,001-9,000$ per acre & 0 & 0 \\
\hline$\$ 9,001-10,000$ per acre & 0 & 0 \\
\hline More than $\$ 10,000$ per acre & 0 & 0 \\
\hline Weighted average $(\$ / \text { acre })^{\mathrm{y}}$ & $2,276.10$ & $2,608.50$ \\
\hline
\end{tabular}

${ }^{\mathrm{z}} \$ 1 /$ acre $=\$ 2.4711 /$ ha.

${ }^{\mathrm{y}}$ The weighted mean was calculated using the median point of the categories.

scenarios. Therefore, the utility in Option C ("Neither A nor B") was normalized to zero, and the all attributes values for Option $\mathrm{C}$ were coded as 0 . Because the fruit diameter variable was described using numerical values in the choice scenarios, these values were used for the estimation. Color and brown rot resistance were qualitative variables, each with three levels. Binary variables were created for each of the levels for these variables with one level serving as the base and omitted from the estimation (to avoid multicollinearity). Parameter estimates should be interpreted as relative to the base variable. The base variable for external fruit color was $50 \%$ red blush color; therefore, parameter estimates for external fruit color should be interpreted as relative to $50 \%$ red blush color. Likewise, the base variable for brown rot resistance was a score of 0 to 2 or very susceptible, and thus parameter estimates should be interpreted as relative to resistance score 0 to 2 .

We assume that $f\left(\beta_{i} \mid \Omega\right)$ is the density function of $\beta_{i}$ with $\Omega=$ $N\left(u_{i}, \sigma^{2}\right)$, and $\varepsilon_{i j}$ is a stochastic identically, independent, distributed extreme value error term that varies over individuals, alternatives, and choices with an expected value of zero, and captures the unobservable effect of individual and alternative attributes. The conditional probability for

Table 5. Parameter estimates for the mixed logit model for selected peach fruit quality and horticultural attributes based on responses from surveys conducted in 2016 and 2018 to southeastern U.S. peach growers.

\begin{tabular}{|c|c|c|}
\hline & 2016 & 2018 \\
\hline \multicolumn{3}{|c|}{ Random parameter estimates - means } \\
\hline Peach diameter & $5.01 * *(2.15)$ & $-0.98(1.18)$ \\
\hline Brown rot resistance score: $>7$, least susceptible & $1.59^{* * *}(0.43)$ & $1.25 * *(0.62)$ \\
\hline Brown rot resistance score: $3-7$, susceptible & $-0.04(0.26)$ & $0.19(0.54)$ \\
\hline External color: $100 \%$ red blush color & $-0.44(0.49)$ & $1.95^{* * *}(0.52)$ \\
\hline External color: $75 \%$ red blush color & $0.46(0.28)$ & $0.76^{* *}(0.38)$ \\
\hline \multicolumn{3}{|c|}{ Random parameter estimates $-S D$} \\
\hline Peach diameter & $1.84 * * *(0.59)$ & $0.85^{* * *}(0.19)$ \\
\hline Brown rot resistance: $>7$, least susceptible & $1.02 *(0.59)$ & $1.26 * * *(0.37)$ \\
\hline Brown rot resistance: $3-7$, susceptible & $0.49(0.43)$ & $0.09(0.86)$ \\
\hline External color: $100 \%$ red blush color & $1.32 * * *(0.43)$ & $0.96^{* *}(0.41)$ \\
\hline External color: $75 \%$ red blush color & $0.53(0.38)$ & $0.43(0.54)$ \\
\hline \multicolumn{3}{|c|}{ Fixed parameters - means } \\
\hline Alternative specific constant-grow option & $-10.84^{*}(5.61)$ & $6.65 * *(3.10)$ \\
\hline Licensing cost & $-0.66^{*}(0.39)$ & $-1.03^{* * *}(0.26)$ \\
\hline Observations (no.) & 504 & 807 \\
\hline Log likelihood & -106.82 & -159.21 \\
\hline
\end{tabular}

* $, * *,{ }^{* *}$ Significant at $P \leq 0.10,0.05$, or 0.01 , respectively. 
Table 6. Willingness to pay for selected peach fruit quality and horticultural attributes responses from surveys conducted in 2016 and 2018 to southeastern U.S. peach growers.

\begin{tabular}{lcc}
\hline Attribute & $\mathbf{2 0 1 6}$ & $\mathbf{2 0 1 8}$ \\
\hline Brown rot resistance score from 0 to 2 to $>7$ & $2.38[0.36,15.96]$ & $1.21[0.01,3.48]$ \\
Brown rot resistance score from 0 to 2 to $3-7$ & - & - \\
Peach diameter $[0.25$-inch $(0.635-\mathrm{cm})$ increments] & $1.89[0.65,6.96]$ & - \\
External color: from $50 \%$ red blush color to $100 \%$ & - & $0.73[0.03,1.69]$ \\
External color: from $50 \%$ red blush color to $75 \%$ & - & $1.89[1.16,2.86]$ \\
\hline
\end{tabular}

grower $i$ to choose alternative $j$ can be expressed as follows:

$$
\begin{aligned}
& L_{i}\left(\Upsilon_{i}=j \mid \beta_{i}\right) \\
& \quad=\frac{\exp \left(\alpha_{i j}+\beta_{i} x_{j}+\gamma z_{i}\right)}{\sum_{k \in M} \exp \left(\alpha_{i k}+\beta_{i} x_{j}+\gamma z_{i}\right)} j \neq k
\end{aligned}
$$

When $\beta_{i}$ is known, the IIA assumption holds, resulting in the standard logit model. When $\beta_{i}$ is not known, the unconditional choice probability is the integral product of $P_{i}\left(\beta_{i}\right)$ overall values of $\beta_{i}$ :

$$
P_{i}\left(\Upsilon_{i}=j\right)=\int L_{i}\left(\Upsilon_{i}=j \mid \beta_{i}\right) f(\beta \mid \Omega) d \beta
$$

The preceding choice probability cannot be calculated analytically, and consistent with other studies, it was solved through simulations (Train, 2009). A mixed logit model allows the random components of the alternatives by relaxing the IIA assumption, and here random preference heterogeneity is expected in response to the peach attributes. Therefore, each model is a mixed logit model with random parameters for all peach attributes (fruit diameter, external fruit color, and brown rot resistance). The cost coefficient is assumed fixed to ensure that all respondents have a negative cost coefficient so that the estimated WTP will be normally distributed (Revelt and Train, 1998).

The WTP for a unit level change of a given attribute for a peach cultivar is the marginal rate of substitution between the cultivar attribute levels and the licensing cost. Because the peach grower's profit function was a linear function of peach cultivar attributes, the WTP was simply the ratio between estimated parameters for the attribute and licensing cost. To calculate the SD of each WTP, we used the method by Krinsky and Robb (1986), which involved 1000 random draws from a normal distribution and 1000 simulated WTPs to calculate the SE. The actual diameter magnitude in inches was used in the estimation, but the choice options presented in the survey considered 0.25 -inch differences, then the calculation of the WTP values used were rescaled (divided by 4 ) to put them relative to the more realistic 0.25 inch-diameter intervals.

\section{Results and discussion}

G R O W E R A N D F A R M CHARACTERISTICS. Summary statistics for the sample peach operations' characteristics, for each year the survey was conducted, are presented in Table 3 . We present first, the summary statistics for the survey conducted in 2016 , and then for the survey conducted in 2018.

For the survey conducted in 2016, data from 32 respondents were available for analysis after one response was dropped because of incomplete information. Of these, 13 responses were from peach operations located in North Carolina, 9 in South Carolina, and the remaining 10 in Georgia. The average operation size in the reference year 2015 was 207.11 acres in South Carolina, 275.15 acres in Georgia, and 11.26 acres in North Carolina. The 2017 Census of Agriculture reported that the average size of peach farms was 70.8 in South Carolina, 4l.1 in Georgia, and 2.9 in North Carolina (USDA, 2017). Compared with the 2017 Census of Agriculture, the farm size in our sample of respondents is skewed to larger farm sizes. The total acreage for the sample of peach operations from Georgia, South Carolina, and North Carolina, in which the farm size question referred to year 2015, was 4762 acres. The total bearing acres of peaches in 2015 for these states was 25,200 acres (USDA, 2018). Therefore, the sample of respondents in the
2016 survey represented 19\% of the total bearing peach acreage for these states. On a 1 to 10 scale ( $1=$ unwilling to take the risk, $10=$ very prepared to take the risk), respondents indicated a risk-taking attitude at an average of 6.72 .

Peach principal operators responses to questions about experiences controlling brown rot disease, and the summary of the responses obtained, for each year the survey was conducted, is presented in Table 4. For the survey conducted in 2016 referring to production year 2015, $23.33 \%$ of the respondents indicated they had experienced crop loss due to brown rot. On average, respondents reported expenses of $\$ 140.50 /$ acre to control brown rot, for production year 2015. This amount represented $6 \%$ of the total variable costs reported by surveyed peach operations at an average at $\$ 2276 /$ acre.

For the survey conducted in 2018,22 responses were from peach operations located in Alabama, 11 in South Carolina, 7 in Georgia, 5 in North Carolina, and 2 in Virginia, making a total of 47 responses. The average acreage operation size in the reference time period 2012-17, was 30.2 in Alabama, 627.16 in South Carolina, 833.81 in Georgia, 15.6 in North Carolina, and 379.75 in Virginia. The 2017 Census of Agriculture reported that the average size of peach farms was 6.2 in Alabama, 70.8 in South Carolina, 41.1 in Georgia, 2.9 in North Carolina, and 3.1 acres in Virginia (USDA, 2017). Meanwhile, in the 2012 Census of Agriculture, the average size was 7.8 in Alabama, 57.3 in South Carolina, 54.7 in Georgia, 3.5 in North Carolina, and 4.1 acres in Virginia (USDA, 2017). Similar to the sample of respondents to the 2016 survey, the farm size in the sample of respondents for the 2018 survey is skewed to larger farm sizes, as reported by the USDA. The average acreage for the 
sample of peach operations from Alabama, South Carolina, North Carolina, Georgia, and Virginia in the 2018 survey, in which the farm size question referred to 2012-17, was 14,237 acres. The total bearing acreage of peaches for 2012-17 for these states was 25,617 acres (USDA, 2019 ), indicating that the sample in the 2018 survey represented 56\% of the total bearing acreage for these states. The self-reported risk attitude was 5.76 ( $1=$ unwilling to take the risk, $10=$ very prepared to take the risk). When responding to questions about experiences controlling brown rot disease for 2012-17, the percentage of respondents who indicated they experienced crop loss due to brown rot was $47.83 \%$. The reported expenses to control brown rot, for the same years 2012-17, was $\$ 224.47$ /acre, representing $9 \%$ of the total variable costs reported by surveyed peach operations at an average at $\$ 2608.50 /$ acre.

GROWER PREFERENCES FOR PEACH QUALITY. Results from the mixed logit model are presented in Table 5. Similar to the previous section, we present first, results for the survey conducted in 2016, and then for the survey conducted in 2018.

In the 2016 sample, the coefficient estimates for fruit size and brown rot resistance at the least susceptible level (score $>7$ ) were positive and statistically significant for the utility derived by a grower when planting a peach cultivar. Growers in this 2016 sample of respondents considered fruit size and a high level of brown rot resistant as variables to take into consideration when deciding to grow a new peach cultivar. The SD for peach diameter, brown rot resistance least susceptible, and external color $100 \%$ red blush were statistically significant, denoting heterogeneity across respondents in their preference for these attributes. The parameter estimate for the alternative specific constant-grow option was statistically significant and negative, indicating growers derive lower utility when growing a peach cultivar as presented in alternatives $A$ and $B$ than when they do not. Also, the mean parameter estimates for licensing costs was negative and statistically significant for the utility derived from paying an upfront licensing fee.

In the 2018 sample, the coefficient estimates for the least susceptible level (score $>7$ ) of brown rot resistance, external color $100 \%$ red blush, and the external color $75 \%$ red blush were positive and statistically significant for the utility derived by the grower when planting a peach cultivar. These results indicate that growers in the 2018 sample of respondents considered external fruit color and the highest level of brown rot resistance as important variables when deciding to grow a new peach cultivar. The SD for peach diameter, least susceptible level of brown rot resistance, and external color 100\% red blush were statistically significant, denoting heterogeneity across respondents in their preference for these attributes. The parameter estimate for the alternative specific constant-grow option was positive and statistically significant, indicating growers derive a higher utility when growing a peach cultivar as presented in the choice scenarios. The mean parameter estimates for licensing costs were negative and statistically significant for the utility derived from paying an upfront licensing fee.

WTP for attributes with statistically significant mean parameters are reported in Table 6 . We present first the results for the survey conducted in 2016 , and then for the survey conducted in 2018. Growers responding to the 2016 survey were willing to pay a licensing fee of $\$ 2.38 /$ tree for an improvement in relative resistance score [going from 0 to 2 (very susceptible) to $>7$ (least susceptible)] Because the WTP estimate was divided by 4 to transform the WTP per 1 -inch increment to a WTP per 0.25 inch increment, the WTP for improvements in fruit size was at $\$ 1.89$ /tree. Meanwhile, growers responding to the 2018 survey were willing to pay a licensing fee of $\$ 1.21 /$ tree for an improvement in relative resistance score [going from 0 to 2 (very susceptible) to $>7$ (least susceptible)]. The WTP for an increment in the red blush color from $50 \%$ to $100 \%$ red blush was $\$ 0.73 /$ tree and an improvement in the fruit color from $50 \%$ to $75 \%$ red blush was $\$ 1.89 /$ tree.

In general, the WTP values reported in this study are consistent with extension educators' observations that southeastern peach growers pay in general $\$ 2$ to $\$ 4$ per tree premium for a patented tree, including the scion and rootstock royalties combined. These results are also consistent with previous literature that external fruit color and fruit size were important for growers' acceptance of a new cultivar (Park and Florkowski, 2003; Yue et al., 2014, 2017; Zhao et al., 2017).

\section{Conclusions}

Differences in the WTP values for each attribute and in the relative importance of brown rot disease resistance vs. size and external color underscore the importance of growers' decisions when selecting a new peach cultivar to grow. Information about WTP for a cultivar with higher disease resistance can assist peach breeders and extension educators in their efforts to reduce the amount of pesticide use in peach production. In addition, the preference for peach quality attributes of size and color suggested the importance of better and consistent quality for new peach cultivars.

Consumers' preferences for superior quality, in terms of appearance, taste and texture attributes, and attributes related to human and environmental health, such as reduced pesticide application, are becoming more important. Plant breeding programs are challenged to develop cultivars with the combination of attributes that meet expectations of all supply chain members. In this study, we estimated the WTP for fruit quality and disease resistance attributes for southeastern U.S. peach growers. This sector presents an interesting case, as growers need to produce cultivars exhibiting superior fruit quality in an environment conducive to high levels of disease pressure.

The sample of peach growers who responded to the 2016 survey placed a greater importance on the fruit quality attribute that would be expected to result in higher returns, that is, fruit size (expressed as fruit diameter) compared with improvements in brown rot resistance and external fruit color. However, this was not observed for the sample of peach growers who responded to the 2018 survey results. One consistent result across the sample of respondents in 2016 and 2018, was that growers would be willing to pay for larger rather than smaller improvements in brown rot resistance. Our results suggest that a large 
improvement in brown rot resistance was more important than external fruit color in both years the survey was conducted.

Peach growers in the United States face multiple challenges, including high start-up and labor costs, weather perturbations and temperature fluctuations that are intensifying with climate change, new pests and diseases, environmental considerations linked to pesticide use, and a decline in consumer demand (Crassweller et al., 2016). Previous studies have evaluated growers' preferences for fruit quality attributes, but few have evaluated the relative importance between fruit quality attributes and disease resistance. Our findings suggest plant breeders must carefully balance grower and consumer preferences, but in the sensitive fresh peach marketplace, consumer demand for fruit quality attributes may supersede grower interest in disease-resistant cultivars. Findings in our study are limited to a crop within a region, and within this context, are limited to the selected fruit quality traits, external fruit color and fruit size, and the disease brown rot included, therefore specific numbers might not be generalized. However, our focus on preferences for attributes that are impacted by both production and marketing conditions is valuable for other researchers focused on growers' decision making when deciding to invest in improved cultivars.

\section{Literature cited}

Campbell, B.L., S. Mhlanga, and I. Lesschaeve. 2013. Consumer preferences for peach attributes: Market segmentation analysis and implications for new marketing strategies. Agr. Resource Econ. Rev. 42:518-541.

Chavez, D., M. Florkowska, J. Cook, and E. Little. 2015. Home garden peaches. 8 Aug. 2018. <https://secure.caes.uga. edu/extension/publications/files/pdf/ C\%201063_2.PDF>.

Choi, J.W., C. Yue, J. Luby, S. Zhao, R.K. Gallardo, V. McCracken, and J. McFerson. 2017. Estimating strawberry attributes' market equilibrium values. HortScience 52:742-748.

Cook, R., D. Peacock, J. Malensky, and D. Granatstein. 2015. Marketing What's the future for fresh, processed, and organic markets? Things you must think about before starting or expanding pro- duction. 21 Sept. 2018. <https:// extension.oregonstate.edu/sites / default/files/documents/1/063-067irrigationscheduling.pdf $>$.

Crassweller, R.M., L.F. Kime, and J.K. Harper. 2016. Peach production. 1 Aug. 2018. <https://extension.psu.edu/ peach-production $>$.

Delgado, C., G.M. Crisosto, H. Heymann, and C.H. Crisosto. 2013. Determining the primary drivers of liking to predict consumers' acceptance of fresh nectarines and peaches. J. Food Sci. 78:605-614.

Dillman, D., J.D. Smyth, and L.M. Christian. 2009. Mail, Internet, and mixed mode surveys: The tailored design method. Wiley, New York, NY.

Gallardo, R.K., D. Nguyen, V. McCracken, C. Yue, J. Luby, and J. McFerson. 2012. An investigation of trait prioritization in rosaceous fruit breeding programs. HortScience 47:771-776.

Gallardo, R.K., H. Li, V. McCracken, C. Yue, J. Luby, and J. McFerson. 2015. Market intermediaries' willingness to pay for apple, peach, cherry, and strawberry quality attributes. Agribusiness 31:259-280.

Georgia Department of Agriculture. 2017. Commissioner Black and Chairman McCall tour freeze damage. 26 May 2020 . <http://agr.georgia.gov/ commissioner-black-and-chairmanmccall-tour-freeze-damage.aspx $>$.

Iezzoni, A. 2018. ROSBREED: Combines disease resistance with horticultural quality in new rosaceous cultivars. 2 Aug. 2018. <https://reeis.usda.gov/web/ crisprojectpages/1004205-rosbreedcombining-disease-resistance-withhorticultural-quality-in-new-rosaceouscultivars.html>.

Krinsky, I. and A.L. Robb. 1986. On approximating the statistical properties of elasticities. Rev. Econ. Stat. 68:715-719.

Lusk, J.L. and D. Hudson. 2004. Willingness-to-pay estimates and their relevance to agribusiness decision making. Appl. Econ. Perspect. Policy 26:152-169.

Moing, A., J.L. Poëssel, L. SvanellaDumas, M. Loonis, and J. Kervella. 2003. Biochemical basis of low fruit quality of Prunus davidiana, a pest and disease resistance donor for peach breeding. J. Amer. Soc. Hort. Sci. 128:55-62.

Olmstead, M.A., J.L. Gilbert, T.A. Colquhoun, D.G. Clark, R. Kluson, and H.R. Moskowitz. 2015. In pursuit of the perfect peach: Consumer-assisted selection of peach fruit traits. HortScience 50:1202-1212.
Park, T.A. and W.J. Florkowski. 2003. Selection of peach cultivars and the role of quality attributes. J. Agr. Resource Econ. 28:138-151.

Pimentel, D. 2005. Environmental and economic costs of the application of pesticides primarily in the United States. Environ. Dev. Sustain. 7:229-252.

Revelt, D. and K. Train. 1998. Mixed logit with repeated choices: Households' choices of appliance efficiency level. Rev. Econ. Stat. 80:647-657.

Ritchie, D.F., M. Parker, K.A. Sorensen, J.R. Meyer, and W.E. Mitchem. 2005. Crop profile for peaches in North Carolina. 3 Aug. 2018. <https://ipmdata. i p m centers.org/d ocuments / cropprofiles/Ncpeach2005.pdf>.

Schnabel, G., A. Amiri, and P. Brannen. 2010. Sustainable brown rot management of peaches in the southeastern United States. Otlk. Pest Mgt. 21:208-211.

South Carolina Department of Agriculture. 2017. Freezing temperatures devastate South Carolina farmers. 26 May 2020. <https://agriculture.sc.gov/ freezing-temperatures-devastate-southcarolina-farmers $/>$.

Train, K.E. 2009. Discrete choice methods with simulation. Cambridge Univ. Press, Cambridge, UK.

U.S. Department of Agriculture. 2017. 2017 Census volume 1, chapter 1: State level. 26 May 2020. <https://www.nass. usda.gov/Publications/AgCensus / $2017 /$ Full_Report/Volume_1, Chapter_1_State_Level/>.

U.S. Department of Agriculture. 2018. Non-citrus fruit and nuts 2017 summary. 26 May 2020. <https://www.nass.usda. gov/Publications/Todays_Reports/ reports/ncit0618.pdf>.

U.S. Department of Agriculture. 2019. Non-citrus fruit and nuts 2018 summary. 26 May 2020. <https://www.nass.usda. gov/Publications/Todays_Reports / reports/ncit0619.pdf>.

Wang, J., C. Yue, R.K. Gallardo, V. McCracken, J. Luby, and J. McFerson. 2017. What consumers are looking for in strawberries: Implications from market segmentation analysis. Agribusiness 33: 56-69.

Yue, C., R.K. Gallardo, J.J. Luby, A.L. Rihn, J.R. McFerson, V. McCracken, T. Gradziel, K. Gasic, G.L. Reighard, J. Clark, and A. Iezzoni. 2014. An evaluation of US peach producers' trait prioritization: Evidence from audience surveys. HortScience 49:1309-1314.

Yue, C., R.K. Gallardo, V. McCracken, J. Luby, J. McFerson, L. Liu, and A. 
Iezzoni. 2012. Technical and socioeconomic challenges to setting and implementing priorities in North American rosaceous fruit breeding programs. HortScience 47:1320-1327.

Yue, C., S. Zhao, R.K. Gallardo, V. McCracken, J. Luby, and J. McFerson. 2017. U.S. producers' willingness to pay for improvement in rosaceous fruit traits. Agr. Resource Econ. Rev. 46:103-122.
Zapata, S.D. and C.E. Carpio. 2014. The theoretical structure of producer willingness to pay estimates. Agr. Econ. 45:613623.

Zhao, S., C. Yue, J. Luby, R.K. Gallardo, V. McCracken, J. McFerson, and D.R Layne. 2017. U.S. peach producer preference and willingness to pay for fruit attributes. HortScience 52:116-121.

Zheng, X., C. Yue, R.K. Gallardo, V. McCracken, J. Luby, and J. McFerson.
2016. What attributes are consumers looking for in sweet cherries? Evidence from choice experiments. Agr. Resource Econ. Rev. 45:124-142.

Zhou, R., C. Yue, S. Zhao, R.K. Gallardo, V. McCracken, J. Luby, and J. McFerson. 2018. Using market segmentation analysis to identify consumer preferences for fresh peach attributes. HortScience 53: 1664-1668. 